\title{
Strategies for Developing Modern Administrators' Change Leadership at Mahamakut Buddhist University
}

\author{
Surasit Kraisin ${ }^{1}$, Pha Agsonsua ${ }^{1} \&$ Prayuth Chusorn ${ }^{1}$ \\ ${ }^{1}$ Faculty of Education, Northeastern University, Thailand \\ Correspondence: Prayuth Chusorn, Faculty of Education, Northeastern University, Thailand.
}

Received: April 11, 2020

Accepted: May 24, $2020 \quad$ Online Published: August 26, 2020

doi:10.5539/ies.v13n9p58

URL: https://doi.org/10.5539/ies.v13n9p58

\begin{abstract}
This mixed methods research has main objectives consisting of investigating the components and creating strategies for the development of change leadership in the modern age among the administrators of Mahamakut Buddhist University. The sample consisted of administrators, teachers, and officers working in Mahamakut Buddhist University. Based on the implications of Krejcie and Morgan's (1970) table for sample size allocation, a total of 262 samples were recruited. The quality of the research instruments can be verified by the content validity and reliability with an IOC of between $0.80-1.00$ and a reliability of 0.98 . The current existing condition of the change leadership for both the overall and the itemized analysis was found to be at a "Moderate level". The strategies for the development of change leadership in the modern age among the administrators of Mahamakut Buddhist University had consisted of the following: 1) six measures for participation at work, 2) seven measures for collective vision, 3) six measures for the promotion of Wisdom exercises, 4) five measures for incentive and inspiration creation, and 5) six measures for promotion of teamwork.
\end{abstract}

Keywords: strategies, change leadership, Mahamakut Buddhist University

\section{Introduction}

As never before seen in university management, those changes, which have taken place in society, the economy, and in politics and that have had the greatest effect, have been responses to the influences of globalization. These changes reinforce the fact that the universities have had to find a new model for their educational management in order to maintain their academic standards and to cater to the needs of their communities'. Following the trends of globalization, it is speculated that the number of students, who will pursue higher education, will dramatically rise in the 21 st century. Despite the increasing demand of a university level education, the higher-level academies suffer from proportionally inadequate budgetary support from the government. Moreover, the expansion of higher education in both the public and private sectors in some countries is suffering from ill-conceived planning. Trauma, arising from the attempts to over-commercialize education, has had hazardous effects on the country and has damaged the educational chances for some people. This misconduct especially rips off the philosophy related to the term, "university" (Pasana, 2018).

In university management, it is more conventional to the extent that the administrators are those reckoned in the higher instructional profession, who periodically take a turn at harnessing the university. Despite their teaching proficiency, this group of administrators lacks business skills. Moreover, their administration track usually begins with being a Department Head, a University Council member, or the Chairperson of a curriculum, among others. Due to the fact that they have experience working in these positions, the administrators are good at analytical thinking, persuasion, understanding the university culture, and taking part in collective decision-making. These skills fit them well in the role of mid-sized administrators. However, higher levels of proficiency and leadership for change are still required when acting as the Head of a university (Gibson, Ivancevich, \& Donnelly, 1997).

\section{Literature Review}

Change Leadership is a process that creates motivation and behavior of leaders in which the leader makes positive changes happens. This relies on the leaders' ability to increase the capacity of the organization's membership and to empower them to make changes to their work objectives and to their work measures. In order to convince the people to get on board with the changing voyage and to accept the higher organizational vision, the following five 
components must be exercised:

\section{1) The Creation of a Shared Vision}

This means the allocation of policies, goals, and the direction toward the university's achievement. The principle behind the idea of having a shared vision is to engage all of the related sectors in implementing the university's missions. The big picture of organizational success needs to be set. Moreover, it is important for the related factors, which can help to propel the organization towards that goal, such as the institution's weaknesses and strengths, to be taken into consideration when establishing the organizational missions and when implementing the plan.

\section{2) The Creation of Incentives and Inspiration}

In the course of carrying out their duties, the administrators provide mental support, incentives, and proper rewards for the organization's members, who are working under pressure. The incentive from the leaders is a force that compels the workers to contribute actively to the completion of the mission. With inspiration from their leaders, the workers tend to gain self-esteem, be more conscientious at work, and take more responsibility for their duties.

\section{3) The Promotion of Wisdom Exercise}

This relates to a leader's ability to trigger systematic thinking and to empower workers to reach their fullest potential under the present working conditions, as well as within a limited budget and in a limited amount of time. The leaders establish themselves as role models in the areas of creativity and in the use of critical thinking skills in problem solving.

\section{4) The Promotion of Teamwork}

This directly refers to a leader's ability to create a culture of teamwork in which people contribute to the collective organizational achievements. When operating as a team, members of an organization learn to aggregate their personal thinking with the team's opinion, which propels collective achievements. In an atmosphere of teamwork, reason is the baseline for making decisions, and emotions are to be put aside when making complex decisions. People are encouraged to trust and to exchange of work innovations in order to help to achieve the university aims.

\section{5) The Promotion of Participation}

This process involves taking into account the local wisdom in the course of arranging the university's implementation plan. Local stakeholders should be engaged in the entire undertaking of Educational Management starting from the planning stage, to the implementation stage, and finally, to the evaluation processes.

Suffice it to say, the measures that have been undertaken by the university's leaders and the type of leadership that has been exercised are the indicators of either the success or failure for any university. There have been numerous research studies examining the procedures of educational administration. In fact, it has been well-documented that both behaviors and administration skills are crucial tools to measure a school's performance based on the educational administrators. Katz (1974) postulated the number of required skills, which includes technical skills, human skills, and conceptual skills, and determined these to be the baselines of the achievement for the school administration. Hoy and Miskel (2001) noted that the degrees of educational success rely solely on the sharing of responsibility among the school's stakeholders, such as teachers, parents, students, and the embed community.

Mahamakut Buddhist University was first established in 1893 under the Royal Approval of King Rama V in order to provide higher education for the Thai Buddhist monks. The conventional working culture of the university, which has been used for over a century, has now been deemed "obsolete" since it does not comply with modern-day culture. Conversely, proper educational innovations have been introduced in other types of religious management and have yielded higher levels of efficiency in Educational Management. It is crucial for Mahamakut Buddhist University to accomplish the following: to employ newer strategies, to develop change leadership, and to establish a conceptual framework for the university in order to bring about higher educational efficiency (Annual Report, 2017).

As a high-ranking administrator, who is in charge of all level administrations at the Roi-Et Campus of Mahamakut Buddhist University, the researcher is interested in conducting a research study to explore the establishment of change leadership in the modern age, which should help the university to obtain higher levels of efficiency and to enhance more sustainable development.

\section{Objectives}

1) To investigate the components and indications of the measure for the development of change leadership in the modern age at Mahamakut Buddhist University.

2) To study the current situation, the preferable characteristics of leadership, and the needs assessment for the 
development of change leadership in the modern age.

3) To create strategies of change leadership in the modern age at Mahamakut Buddhist University.

\section{Research Methodology}

Population and Sample, the following scope of population and sampling were specified based on their correlations with the research questions and the research objectives.

1) The population consisted of 813 people and monks, who were administrators, teachers, and working staff members at Mahamakut Buddhist University.

2) Based on the population in Number 1 and the table of sample size allocation designed by Krejcie and Morgan (1970) a total number of 262 samples were recruited using the Stratified Random Sampling method and the Simple Random Sampling method.

3) Samples, who participated in the interviews, consisted of 7 Vice-Presidents (some were monks), 23 Monk Directors, and 7 Presidential Assistants (some were monks).

4) The Focus Group Discussions comprised 13 people: 5 Administrators/Monks, 3 University Academics, and 5 Scholars with expertise in Educational Administration. All of these participants were selected via the purposive sampling method.

The instrument used for this research study was Interview Forms and Questionnaire Forms.

1) The Interview Form

In the interview form were the questions that were used to help gauge information about the current situation, the preferred trends, and the need of change leadership in the modern age. The questionnaire focused on 7 aspects as follows: 1) the creation of a collective vision, 2) the creation of incentives and inspiration, 3) the activation of the usage of Wisdom, 4) the continuity of professional development, 5) the creation of the individual's boundary with the university, 6) the promotion of teamwork, and 7) the promotion of participation.

2) The Questionnaire Form

There were two parts in this questionnaire form as follows:

Part 1: General Information about the Informants.

This portion involved the participants by asking them to answer questions about themselves based on the checklist answers.

Part 2: The Informant's Ideas about the Current Situations for Change Leadership.

This section involved the samples by asking them to answer a set of five scale questions.

The processes of instrument creation and quality:

The documents, which were related to the development of change leadership in the modern age, were studied. The revised version of the questionnaire was shown to the 5 experts so that they could evaluate the coherence of the questions and their alignment with the research objectives and to the definitions of terms. In this process, the Index of Item-Objective Congruence (IOC) was rated at 0.80-1.00 (Somnuk, 2003).

\section{Result}

In the modern age the change leadership particularly for Mahamakut Buddhist University should consist of the following:1) participation at work, 2) collective vision, 3) the promotion of Wisdom Exercises, 4) the creation of Incentives and inspiration, and 5) the promotion of teamwork. The current existing condition of the change leadership in modern age at Mahamakut Buddhist University, for both the overall and the itemized analysis, was found to be at a "Moderate level", while the preferred condition based on the overall and the itemized investigation was found to be at a "High" level. Based on the intersection point at 3.50 of the current condition and the preferred condition of Leadership, the matrix analysis revealed that the five strategies of leadership had been poorly performed and needs assessment to be made. The strategies for the development of change leadership in the modern age among the administrators of Mahamakut Buddhist University had consisted of the following: 1) six measures for participation at work, 2) seven measures for collective vision, 3) six measures for the promotion of Wisdom exercises, 4) five measures for incentive and inspiration creation, and 5) six measures for promotion of teamwork.

Strategy 1: Participation at Work

Goal: To encourage participation via the establishment of a collective goal. 
The Measures:

1) Having trust among the members

2) Exchanging expertise in order to solve problems

3) Exploiting the Local Wisdom for the purposes of Educational Management

4) Exercising the plan

5) Promoting collaboration among the members

6) Participating in establishing the agreements

The Indicators of Success:

1) The percentile of the project's achievements

2) The percentile of the achievements of the learning exchange activities

3) The percentile of the achievement of using Local Wisdom for Educational Management

4) The percentile of the achievement in the completion of the established goals

5) The percentile of the achievement of the activities

6) The percentile of the achievement in negotiating the establishment of agreements

Strategy 2: The Creation of the Collective Vision

Goals: To activate systematic thinking and creativity

The Measures:

1) Integrating the ideas of all of the stakeholders into the creation of the university's missions and measures

2) Evaluating the related factors, such as institutional weaknesses and strengths and then applying them to the mission and strategies

3) Setting the example by being a good role model

4) Communicating clearly

5) Implementing the plan

6) Allocating goals and the direction for the organization

7) Establishing concrete achievements

The Indicators of Success:

1) The percentile of achievements in mission setting

2) The level of success in evaluating the related internal and external factors and the evaluation of weaknesses and strengths

3) The percentile of achievement for the establishment of a good role model

4) The percentile of the achievements of activities

5) The percentile of the goals, which had been accomplished

6) The percentile of the satisfaction with respect to the allocation of policies, missions, and the aims of the university

7) The percentile of the achievement in setting the preferred achievements of leadership

Strategy 3: The Activation of the Usage of Wisdom

Goal: To promote continuous self-development among the staff members.

The Measures:

1) Having the ability to creatively solve unforeseen problems as they arise

2) Promoting the proper use of the correct technology at work

3) Hosting activities that foster skills and provide training for the staff members

4) Providing suggestions for achievements at work

5) Promoting continuous self-development 
6) Having the freedom to choose the activities for personnel development

The Indicators of Success:

1) The percentile of the staff member's satisfaction regarding the use of their creativity to solve unforeseen problems

2) The percentile of the personnel members, who have been trained to use technology for job enhancement

3) The percentile of the personnel members' level of satisfaction concerning activities that had previously been hosted for professional development

4) The percentile of the activities that have been conducted to achieve the established goals

5) The percentile of the success of the activities that have promoted continuous self-development

6) The percentile of the staff members' levels of satisfaction on the selection of the activities for personnel development

Strategy 4: The Creation of Incentives and Inspiration

Goal: To promote inspiration and incentives for the staff members.

The Measures:

1) Thinking and working systematically

2) Being conscientious and taking responsibility for their duties

3) Having a leader as a role model, who exhibits creativity and innovation

4) Providing rewards, compliments, and incentives to raise the spirits of the staff members

5) Taking administrative actions that encourage achievements by making decisions under the constraints of limited time and a limited budget

The Indicators of Success:

1) The percentile of the success of the activities

2) The percentile of the staff members' levels of satisfaction concerning the performance of the administrators

3) The percentile of the staff members' levels of satisfaction concerning the establishment of the leaders as role models

4) The percentile of the staff members' levels of satisfaction concerning the provision of incentives and rewards performed by the leaders on different occasions

Strategy 5: The Promotion of Team Learning and Collective Problem-solving

Goal: To promote team learning and collective problem-solving.

The Measures:

1) Forming a team of working Committee members to implement the educational development plan using the participatory technique

2) Allocating those aims and activities that encourage team learning based on the current circumstances

3) Activating trust and belief among the members with respect to implementing the organizational plan

4) Motivating the staff to work to reach their fullest potential in order to achieve the collective goals

5) Fostering a creative working atmosphere, which activates the participants and encourages them to share their ideas for solving problems in the long term

6) Activating the members' preferences about the organizational systems, regardless of whether it is the administrative system or the work system

The Indicators of Success:

1) The percentile of the projects or activities that have been implemented as part of the educational development plan

2) The levels of success in allocating the objectives and activities that reinforce team learning that are responsive within the existing environment

3) The percentile of satisfaction concerning the performance of the organization 
4) The percentile of the achievement of the activities

5) The level of success in promoting creativity

6) The percentile of the levels of satisfaction concerning the organizational systems, such as the administrative system or the work system

\section{Discussion}

1) Particularly for Mahamakut Buddhist University, change leadership in the modern age consisted of the following: 1) participating at work, 2) having a collective vision, 3) promoting the Wisdom Exercises, 4) creating Incentives and Inspiration, and 5) promoting teamwork. Based on the fact that these five components of leadership have been used by the administrators, their quality of Educational Management will be higher. In order for the organization to achieve its goals, the implementation of the projects should be based on the related measures and on the indicators of success. Coulter (2005) explained that measures are the decisions and actions that achieve the goals. The resources and the potentials of the organization should be deployed in order to protect the organization from any possible risk or harm. Phrakhrukittiwaropakan (2016) investigated the components of leadership for the management of the General Buddhist schools and in the study, the following six areas of leadership were observed: 1) Vision, 2) Etiquette and morale, 3) Allocation of organizational direction, 4) Organizational culture, 5) Control and evaluation of the measures, and 6) Implementation of the measures.

2) The investigation of the current conditions of change leadership in the modern age, which had been observed among the administrators of Mahamakut Buddhist University, showed that the overall and the itemized analysis for all areas of leadership components had been rated at a "Moderate" level. The area with the highest average had been the Promotion of Teamwork, followed by the Activation of Wisdom Exploitation, the Creation of Incentives and Motivation, and the Creation of a Collective Vision. The area with the lowest average score had been Participation at Work. With regard to the preferable type of change leadership in the modern age, it was learnt that the overall and the itemized analysis for all of the leadership components had been rated at a "High" level. The components with the highest average scores had been the Activation of Wisdom Exploitation, followed by the Promotion of Teamwork, the Creation of Incentives and Motivation, and Participation at Work. The leadership value with the lowest score had been the Creation of a Collective Vision. From the Matrix Analysis, which was based on the intersection of the scores at 3.50 from the current situation analysis and from the score of the preferable areas of leadership that had been measured, it was learnt that the scores of the preferable areas of leadership had been at an "Unsatisfactory" level, which underscores the need for development in those particular areas. Barth and Schipper (2008) conducted a research study, which focused upon the role of the leadership to raise team standards by using the reflective reaction method. The research began by developing a form that was focused on reflecting upon the reactions that team members had in response the leaders' behaviors and to raise the level of the team's understanding about it. The model was tested with 32 teams working at 9 different organizations. It was observed that Leadership for Change had been related to the creation of a collective vision and that it had led to higher performance among the team members.

3) The evaluation of the measures for the development of change leadership in modern age in Mahamakut Buddhist University

a) With regard to the measures for the leadership development in Mahamakut Buddhist University, the overall evaluation was rated at the "Highest" level. Measure 2: The Creation of a Collective Vision, had been observed to have the "Highest" average score, which resulted from the fact that the university had conducted a factors analysis and that the university's strengths and weaknesses had been considered when allocating its missions and the university's direction, as well as when determining the objectives and the goals of the university. Moreover, factors, such as establishing the leaders as good role models, having clear communication within the organization, and concretely implementing all elements of the plan, had played a role in making the average score on Measure 2: The Creation of a Collective Vision to be at the "Highest" level. Similar ideas were articulated by Bass and Avolio (1990), who proposed two types of leadership: Transformational Leadership and Transactional Leadership. Under these two type of leadership, changes within an organization take place when its leaders propose ideas that attract the interest of the practitioners. The creation of Motivation at Work raises the commitment of the staff and finally, involves them in becoming Leaders for Change.

b) The assessment of the possibility of the measures for the change leadership in the modern age at Mahamakut Buddhist University had indicated the overall rating to be at a "High" level. Measure 3: The Activation of Wisdom Exercise was found to have had the "Highest" average score. This finding can be explained based on the working culture at this university. Specifically, for their own personal development, each office was given the opportunity to select any activity that they deemed appropriate. Workers were encouraged to use technology to enhance 
performance, while the leaders were reported to have activated their followers to use new and smarter ways to solve problems. Moreover, the followers were encouraged to significantly reflect upon the key values and to specify the clear timelines that they would need to accomplish their goals. Avolio, Waldman, and Einstein (1988) suggested that leaders should demonstrate that they have the ability to analyze the problems and should point out the key effects that properly analyzing the problems can bring to their organizations.

\section{Suggestions}

\subsection{Policy Related Suggestions}

The results concerning the measures for the development of change leadership were determined based on the review of many key documents. In order for the results to be effectively applied within the context of Mahamakut Buddhist University, each office should adapt and be flexible when applying the ideas to their particular portion of the organization based upon its unique characteristics.

There are 5 measures for the development of change leadership in the modern age particularly within the context of Mahamakut Buddhist University. The application of these results should be adapted to make certain that the changes will be suitable for the different offices, which have different natures.

In order to ensure the sustainable development of leadership for their own personal evolution, it is important to create an awareness of the importance of change leadership in the modern age among the working members of an organization.

\subsection{Suggestions for Future Research}

1) Future research should be conducted to test the effects from the application of the measures for the development of Leadership in the modern age and the effects that these measures can have upon the changes in leadership quality among the target leaders.

2) There should be similar research studies that examine the development of leadership to make changes within other universities.

3) There should be future research examining the factors that encourage the successful application of the measures for the development of change leadership within particular contexts of Mahamakut Buddhist University.

\section{References}

Avolio, B. J., Waldman, D. A., \& Einstein, W. O. (1988). Transformational leadership in a management game simulation: Impacting the bottom line. Group \& Organization Studies, 13(1), 59-80. https://doi.org/10.1177/105960118801300109

Barth, M. E., \& Schipper, K. (2008). Financial Reporting Transparency. Journal of Accounting, Auditing \& Finance, 23, 173-190. https://doi.org/10.1177/0148558X0802300203

Bass, B. M., \& Avolio, B. J. (1990). The four Is Transformational Leadership. Journal of European Industrial Training, 115(2).

Coulter, M. (2005). Management (8th ed.). Prentice Hall.

Gibson, J. L., Ivancevich, J. M., \& Donnelly, J. H. (1997). Organization Behavior Structure Process (9th ed.). New York: McGraw-Hill.

Hoy, W. K., \& Miskel, C. G. (2001). Educational Administration: Theory, Research and Practice (6th ed.). McGraw-Hill International.

Katz, E. (1974). The Use of Mass Communication: Current Perspectives on Gratifications Research. Beverly Hill: Sage Publications.

Krejcie, R. V., \& Morgan, D. W. (1970). Determining sample size for research activities. Educational and psychological measurement, 30(3), 607-610. https://doi.org/10.1177/001316447003000308

Pasana, C. (2018). Learning Management for Students in the Thailand 4.0 Era. Veridian E-Journal, Silpakorn University.

Phrakhrukittiwaropakan. (2016). An Approach for Applying Strategic Leadership to the Administration of General Buddhist Scripture School in Khon Kaen. Doctor of Philosophy Program, Educational Administration Northeastern University.

Somnuk, P. (2003). Educational Measurement (4th ed.). Kalasin: Prasan printing. 


\section{Copyrights}

Copyright for this article is retained by the author(s), with first publication rights granted to the journal.

This is an open-access article distributed under the terms and conditions of the Creative Commons Attribution license (http://creativecommons.org/licenses/by/4.0/). 